NASA Technical Memorandum 100891

\title{
NASA Advanced Turboprop Research and Concept Validation Program
}

John B. Whitlow, Jr. and G. Keith Sievers

Lewis Research Center

Cleveland, Ohio

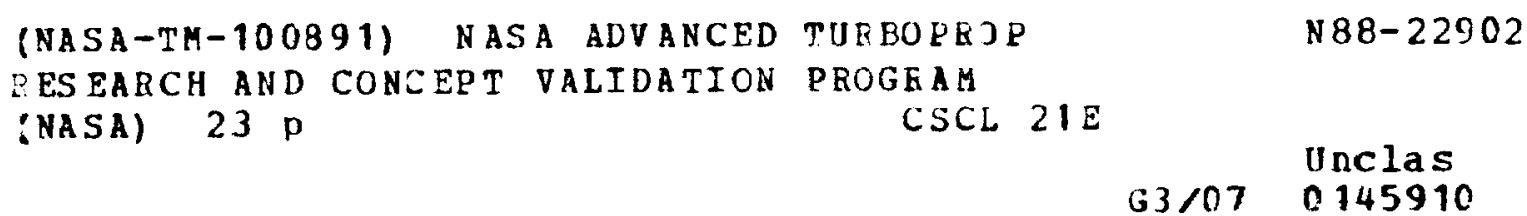

Prepared for the 1988 Conference and Exposition on Future Transportation Technology sponsored by the Society of Automotive Engineers San Francisco, California, August 8-11, 1988

\section{Nusn}



NASA ADVANCED TURBOPROP RESEARCH AND CONCEPT VALIDATION PROGRAM

John B. Whitlow, Jr. and G. Keith Sievers

National Aeronautics and Space Administration

Lewis Research Center

Cleveland, Ohio 44135

\section{SUMMARY}

NASA has determined by experimental and analytical effort that use of advanced turboprop propulsion instead of the conventional turbofans in the older narrow-body airline fleet could reduce fuel consumption for this type of aircraft by up to 50 percent. In cooperation with industry. NASA has defined and implemented an Advanced Turboprop (ATP) program to develop and validate the technology required for these new high-speed, multibladed, thin, swept propeller concepts. This paper presents an overview of the analysis, model-scale test, and large-scale flight test elements of the program together with preliminary test results, as available.

The importance of fuel efficiency in future aircraft designs leads to consideration of advanced turboprop concepts. Old turboprops, such as those found on the Lockheed Electra/P-3 Orion and C-130 (upper left part of fig. 1), were fuel efficient up to airspeeds of slightly over Mach 0.6. Beyond these speeds, however, these propellers experience a rapid increase in compressibility losses due to their thick, unswept, large-diameter blades. Their propulsive efficiency is much higher than that of high bypass turbofans at speeds up to Mach $0.6+$ because of a relatively low disk power loading (SHP/D ${ }^{2}$ ) which imparts only a small increase in axial velocity to a large mass flow of air. The advanced turboprop (or propfan), shown on the lower right in figure 1, overcomes the speed limitations of current turboprops. This design incorporates very thin, highly swept blades which minimize both compressibility losses and propeller noise during high-speed cruise. High disk power loadings (at least double those of the Electra) are required for high-speed cruise to minimize propfan diameter and weight, and allow easier integration with the aircraft. The higher disk loadings are achieved by increasing the blade count and lengthening the blade chord. By incorporating these design features in an advanced propelier, installed propulsive efficiencies roughly equivalent to those achieved with the old Electra technology can be extended to the Mach 0.8 regime.

To put the advanced turboprop fuel savings potential into perspective, these efficiency improvements mean that over half of the fuel consumed by today's U.S. fleet of narrow-body $727^{\prime} \mathrm{s}, 737^{\prime} \mathrm{s}$, DC9's, and MD $80^{\prime} \mathrm{s}$ could be saved by using advanced turboprops. As shown in figure 2, this represents a fuel savings of about 2.5 billion gal/yr. If the comparison is made against improved higher bypass turbofan engines available for installation in the same 1992 timeframe, the advanced turboprop would still provide a savings of about 1.5 billion gal/yr.

The purpose of this paper is to provide an overview of the key elements of the NASA ATP program and related industry programs leading to the validation of advanced turboprop concepts. The discussion will summarize model testing, the development and testing of large-scale hardware, and to some extent, 
the development and verification of analytical design and performance prediction codes. The evolution of the ATP program, its accomplishments, current status of the various elements, and future plans will be briefly discussed.

\section{ATP PROGRAM OVERVIEW}

Figure 3 shows in the top row of pictures the ongoing NASA generic propeller research program of analysis and scale model wind tunnel tests leading to design validation and verification of aerodynamic, acoustic, and structural codes. Advanced concepts of a single-rotation propfan with stator vane swirl recovery and a high-bypass-ratio ducted-fan configuration are illustrated in the bottom row of drawings. While future ducted props will not have the efficiency of unducted propfans, they are more suitable for "packaging" on large aircraft such as the Boeing 747 .

Flgure 4 shows the overall content and flow of that part of the Advanced Turboprop Program orlented toward large-scale hardware in the areas of singlerotation, gearless counterrotation, and geared counterrotation. Knowledge gained from these programs will aid in the design of advanced concepts, such as those alluded to in the preceding figure. Although propfan aerodynamic performance can be accurately assessed at model scale in wind tunnel testing, uncertainties existing with the scaling of structural and acoustic model data led to the large-scale hardware validation program (ref. 1). To reduce progralii cost, existing hardware was modified, where possible, to obtain the flying testbeds for the advanced turboprop hardware.

In four major flight test programs illustrated in figure 5 , high-speed propellers either have been or will be flight tested within a 2-year time span. GE and Boeing led the way in August 1986 with flight tests of the GE Unducted Fan (UDF) propulsion system on the Boeing 727 aircraft. Although not directly involved in this flight test program, NASA supplied from Government inventory the F404 gas generator used initially in the UDF concept demonstrator engine and also participated in the wind tunnel model testing and evaluation of a serles of blade configurations from which the large-scale design was selected. NASA and Lockheed followed in March 1987 with the Propfan Test Assessment (PTA) flight test program which used a modified Gulfstream GII testbed airplane. In May 1987, GE combined with Douglas Alrcraft to flight test the UDF propulsion system on the Douglas MD-80 aircraft. United Technologies, Allison, and Douglas plan to begin another flight test program this year to evaluate a geared counterrotation propfan system installed on the MD-80.

\section{SINGLE-ROTATION SYSTEMS}

The SR-7A propeller model shown in figure 6 is an aeroelastically scaled $2-\mathrm{ft}$ model of the 9-ft-diameter SR-7L propeller used in the PTA flight program. The model is shown in the NASA Lewis 8 - by 6 -Foot wind tunnel, where it was tested for derodynamic, acoustic, and aeroeleastic performance (ref. 2). Also shown in the photograph are laser beams which were part of a system for measuring blade deflections during propeller operation.

The initial wind tunnel evaluations of the aerodynamic and acoustic characteristics of subscale advanced propeller models began at United Technologies Research Center (UTRC) and NASA Lewis in the late 1970's. Some of the earlier 
blade models that were wind-tunnel tested at NASA Lewis (ref. 3) and led to the final SR-7 design are shown in figure 7 .

Net efficiencies of the SR-7 propeller model and some of the earlier models are shown in figure 8 as a function of Mach number (ref. 4). Each propeller's design loading parameter $C_{p} / J^{3}$ was kept constant with Mach number in this plot. At Mach 0.80 the SR-7A propfan has the highest measured propeller efficiency - 79.3 percent. The performance of the SR-2 propeller is lower than that of the others because of its unswept blade design. Design characteristics of these models are indicated in the table below.

An experimental and analytical research program is being conducted to understand the flutter and forced response characteristics of advanced highspeed propellers. A comparison of measured and calculated flutter boundaries for a propfan model, called SR3C-X2, is shown in figure 9 (refs. 5 and 6 ). The theoretical results, from the NASA Lewis-developed ASTROP 3 analysis, include the effects of centrifugal loads and steady-state, three-dimensional air loads. The analysis does reasonably well in predicting the flutter speeds and slopes of the boundaries. However, the difference between the calculated and measured flutter Mach numbers is greater for four blades than for eight blades. This implies that the theory is overcorrecting for the decrease in the aerodynamic cascade effect with four blades.

Peak fundamental tone levels are shown at a constant advance ratio in figure 10 for three loading levels of the SR-7A model at high-speed cruise conditions (ref. 7). The striking feature of the tone varlation with helical tip Mach number is the behavior in the supersonic range beyond Mach 1.1. The peak fundamental tone levels no longer increase and may peak, level off, or decrease depending on loading. This result indicates that higher cruise and propeller speeds do not necessarily mean increased source noise.

Under the Large-Scale Advanced Propeller (LAP) project (ref. 8), Hamilton Standard in late 1985 completed a static rotor test of the 9-ft-diameter SR-7L propfan at a Wright Patterson Air Force Base facility using a $10000 \mathrm{hp} \mathrm{elec-}$ tric drive motor. In early 1986, the LAP was installed in France's Modane wind tunnel to verify blade structural integrity at speeds up to Mach 0.83 . A second Modane tunnel entry occurred in early 1987 to acquire blade steady and unsteady pressure data for verifying and improving aerodynamic prediction codes. Figure 11 describes pictorially the second Modane entry and also shows one of the two completed propfans delivered to the PTA project. Both a primary and backup propfan were delivered to the PTA flight test program.

A two-bladed version of the eight-blade propfan was used in some of the Modane wind tunnel testing because of the limited facility power available to drive the propeller. In this way the propeller could be operated at a reasonable power per blade. The large size of this propeller allowed much more detailed blade pressure measurements than could be obtained on the 2 -ft diameter models tested previously.

Prior to the installation of the instrumented SR-7L propfan on the PTA airplane, a ground static test of the entire propulsion system - including propfan, engine/gearbox, and forward nacelle - was conducted in May and June 1986 at an outdoor thrust stand at Rohr Industries' Brown Field site in California (ref. 9). The purpose of the test was to functionally check out the system and substantiate performance and propfan structural integrity under 
static conditions prior to installation on the modified G-II testbed airplane. Over $50 \mathrm{hr}$ of extensive testing was accomplished, with essentially flawless system operation and with blade stresses at a level somewhat below those seen at the previous WPAFB static rotor test. In neither of these static tests was there any evidence of blade flutter and stresses were low except at very high blade angles representative of high power where buffeting characteristic of separated flow was sometimes indicated. Such behavior at static conditions is not unusual in the development of a new design although it would be desirable through design refinement to eliminate any tendency toward such behavior prior to release of a product design.

Forty-six strain gages were installed on the LAP propfan used in the static test at WPAFB and Rohr and later in flight testing on the G-II testbed at Lockheed-Georgia. Of this total, 30 strain gages were connected through slip rings to the Hamilton Standard data system and continuously recorded during propfan operation while the remainder were spares which could be used in the event of a malfunction of one of the primary gages. Figure 12 shows the LAP being installed on the modified Gulfstream G-II airplane at LockheedGeorgi a.

After G-II aircraft modifications and ground checkout testing in the PTA program, flight testing began in March 1987 (ref. 10). The first tests were conducted with the propfan removed to establish safe aircraft operation before proceeding with prop-on testing in April 1987. Some of the initial prop-on testing is shown in figure 13. In these photos, the fuselage protective shield at the propfan plane of rotation can be seen. This $80-i n$.-long shield, made of $3 / 8-1 n$. stainless steel, was retained on the fuselage during the airworthiness assessment but later removed during the research test phase to facilitate access to fuselage surface microphones. Another unique feature of the PTA is the variable tilt nacelle. A split line on the propfan nacelle just ahead of the wing leading edge can be seen in the lower photo. The forward and aft portions of the nacelle are split at this point to allow the forward nacelle to be tllted up or down so that blade stresses can be assessed as a function of inflow angle.

The PTA flight test program was performed to verify the structural integrity of the large-scale propfan and to characterize its acoustics both outside and inside the cabin as well as on the ground. Stress and acoustic data were obtained over a flight envelope extending from just above low-speed stall to Mach 0.89 at altitudes up to $40000 \mathrm{ft}$. Fly-over and sideline grcund noise measurements were obtained in both high and low altitude flight.

A total of 613 parameters, as indicated in figure 14, were recorded during the PTA research flight tests. These included 127 microphones, 100 accelerometers, 221 pressures, 50 strain gages, and $115 \mathrm{miscellaneous} \mathrm{temperature} \mathrm{and}$ operational parameters. All parameters were recorded on-board at consoles where Hamilton Standard and Lockheed test engineers monitored selected data channels during the tests. A telemetry system was used to transmit selected operational parameters to a ground-based recorder.

Several scale-model tests were conducted in the PTA program (fig. 15) to help ensure a safe flight test program and to obtain data for validating aerodynamic prediction codes. The 1/3-scale S-duct diffuser model test verified that high levels of total pressure recovery would be obtained with low levels of flow distortion at the compressor face (ref. 11). A 1/9-scale airplane 
aeroelastic model was successfully tested in the NASA Langley Transonic Dynamics Tunnel to verify the adequacy of the airplane flutter-prevention modifications and to validate the flutter analysis techniques (ref. 12). Another 1/9-scale model was built and tested to evaluate aerodynamic performance, stability, and control, and tested at NASA Langley in both high-speed (ref. 13) and low-speed wind tunnels with both powered and unpowered propfan. The results showed excellent agreement with predictions based on computational aerodynamics. A rake survey of the flowfield at the propfan plane was also conducted in the NASA Lewis 8 - by 6-Foot high-speed tunnel with a $1 / 9$-scale semispan model to verify the flowfield prediction code (ref. 14). The predicted flowfield at the various flight test conditions was used as a correlation parameter for measured propfan stress.

Initial flight noise test data agree favorably with both scaled-up data from the NASA Lewis 8- by 6-Foot Wind Tunnel and predictions obtained using a Hamilton Standard analytical prediction code (ref. 10). Comparative data along the fuselage exterior surface near the closest points of propfan approach are presented at axial locations fore and aft of the plane of rotation in figure 16. Maximum measured SPL at the fundamental blade passing tone of $225 \mathrm{~Hz}$ was $147 \mathrm{~dB}$. The measured local noise reduction at an adjacent location inside the bare-wall cabin (at 4 in. from the wall) was $25 \mathrm{~dB}$. An advanced cabin acoustic treatment will be required to bring the interior noise level down at least another 25 to $30 \mathrm{~dB}$ for comparability with existing turbofan-powered airliners.

A 10-ft section of the PTA aircraft cabin was cleared for acquiring data with an advanced cabin acoustic treatment. In February and March 1988 an experimental cabin acoustic enclosure was installed and flight tested at a series of flight conditions previously flown with the bare-wall cabin. This treated enclosure was designed and fabricated as part of a NASA Langley contract with Lockheed-California. The enclosure, located as shown in figure 17 , consists of tuned Helmholtz resonator panels attached to a framework which is mounted to the cabin floor through vibration isolators. Preliminary analysis of the data obtained from the 31 cabin interior and 20 fuselage exterior microphones indicate that interior noise levels 25 to $30 \mathrm{~dB}$ below that with the bare-wall cabin were obtained. Upon completion of the flight test, the enclosure was removed from the airplane and shipped back to Lockheed-California for further ground testing.

The PTA flight test effort at Lockheed-Georgia has now been concluded with the completion of the advanced cabin acoustic treatment flights. Although some preliminary results are avallable from the flight test program, because of the massive quantity of data to be analyzed the final results will not be available until October 1988. At this time, however, it is clear that these flights, as intended, verified propfan structural integrity. There was no evidence of flutter anywhere in the flight regime and blade stressing was in good agreement with predictions. Measured blade stresses were within limits established by Hamilton Standard for infinite life. Preliminary acoustic data analys is indicates that magnitudes and trends are generally as predicted with propfan noise slightly lower than predicted.

\section{GEARLESS COUNTERROTATION SYSTEMS}

Counterrotation propeller systems offer further potential gains in propulsive efficiency because of their ability to reduce or eliminate the nonaxial 
or "swirl" component of the discharge flow associated with single-stage props. At Mach 0.8 cruise speeds, this could mean a further efficiency improvement of approximately 8 percent. NASA participated with the General Electric Co. in the development of the unique Unducted Fan (UDF) concept demonstrator engine shown in ground static testing at GE's Peebles, Ohio, outdoor test facility in the top photo of figure 18. This counterrotation UDF engine is unique in that the reduction gearbox common to conventional propeller drive systems is eliminated, with the prop blades being directly driven by a multistage power turbine (ref. 15). The $20000-h p-c l a s s$ concept demonstrator engine uses an F404 turbofan engine as the gas generator ahead of the power turbine; there is no mechanical link between the F404 and the power turbine, which is driven solely by hot exhaust gas from the F404. After successfully completing the Peebles ground testing, the UDF demonstrator was installed on a Boeing 727 airplane for flight testing in August 1986. The engine was later installed on an MD-80 in May 1987 for a Douglas flight test program. These flight test configurations are shown in the two bottom photos of figure 18 .

An important NASA technical contribution to the UDF design was in the wind tunnel evaluation of various model blade designs compatible with UDF requirements. The NASA Lewis counterrotation pusher propeller test rig was supplied under contract by General Electric (ref. 16) and is shown with a UDF blade configuration in the 8 - by 6 -Foot Wind Tunnel in figure 19. These UDF-specific blade designs are characterized by a much higher hub-to-tip radius ratio than the previously tested single-rotation designs because of the large UDF drive turbine diameter which must be accommodated within the hub of the full-size prop. Performance, flow field, and acoustic measurements were made during this testing.

The UDF model blade configurations tested at NASA Lewis included designs for Mach 0.72 cruise (top row of fig. 20) and Mach 0.8 cruise (bottom row). The designs differed in tip sweep, planform shape, airfoll camber, and a significantly shortened aft rotor (A3). The planform shapes for most forward and aft rotors were very similar. The aft rotor planform for $A 21$ is included since it differs so much from the front rotor $\mathrm{F} 21$. The $\mathrm{Fl}-\mathrm{Al}$ configuration is very similar to F7-A7 but with reduced camber, which is expected to improve cruise efficiency. Fl-A3 was run to see the aerodynamic and acoustic effects of a short aft rotor. Both $\mathrm{Fl}-\mathrm{Al}$ and $\mathrm{Fl}-\mathrm{A} 3$ were run with a $9+8$ blade configuration as well as the standard $8+8$. These blades were designed and built by the General Electric Company.

Fundamental tone directivities for the F7-A7 blade combination, the proofof-concept UDF configuration, are shown in figure 21 for scaled model data from the NASA Lewis 8 - by 6 -Foot Wind Tunnel and full-scale flight data obtained by the instrumented NASA Lewis Learjet in formation flights with the UDF-powered 727 (ref. 4). There is excellent agreement among the model wind-tunnel measurements, full-scale fligit data, and prediction at most sideline angles, although the wind tunnel data appear to be somewhat high at forward angles.

\section{CONVENTIONAL COUNTERROTATION SYSTEMS}

NASA has also sponsored research leading to the development of a more conventional geared counterrotating propfan system using blade technology which is basically an extension of that pioneered in the LAP single-rotation propfan. In the Advanced Gearbox Technology Program, Allison has designed, fabricated, 
and tested a high-power advanced counterrotation gearbox (ref. 10). Figure 22 shows this gearbox at Alijison on their new back-to-back gearbox test rig. Modularity of construction for ease of maintainability, high mechanical efficiency, and durability were of paramount importance in this gearbox design. Allison used the results of these tests in developing the technically similar flightweight gearbox for the PW-Allison/Douglas 578DX/MD-80 flight test program.

The CRP-X1 propeller model designed and bullt by Hamilton Standard under contract to NASA Lewis is shown in figure 23 installed in the UTRC high-speed wind tunnel. The front and rear propellers in this model are independently driven by two air-driven turbines. Propeller performance and flow field data (ref. 17), as well as blade stresses, were measured during these tests. Propeller acoustic data were obtained during separate tests in the UTRC Acoustic Research Tunnel (ref. 18). At the Mach 0.8 design power loading, a net efficiency improvement of approximately 6 percent was obtained over the analogous SR-7A single-rotation model. The efficiency also remains high over a wide range of power loadings in a cruise Mach number range of 0.7 to 0.8 . The design of the Hamilton Standard counterrotation propfans used in the MD-80/5780X flight test is based on the technology of the CRP-XI model and the earlier SR-7.

When propfans are operated appreciably away from their cruise design point, such as at takeoff, flow visualization experiments show that a leading edge vortex forms and merges with the tip vortex. The phenomenon is similar to the vortex structure on a delta wing aircraft at high angle of attack during approach. If the associated altered loading distribution is not accounted for in analytical models, errors in aerodynamic performance and noise predictions will result.

An Euler code developed at NASA Lewis (ref. 19) was run at UTRC with an order of magnitude increase in grid points in an effort to analytically simulate this flow phenomenon with the CRP-XI propeller. When particle paths were traced, as shown in figure 24, they revealed the leading edge vortex which merges with the tip vortex flow. The operating condition shown is typical of a takeoff situation involving high incidence angles. Apparently, a numerical "viscosity" factor included in the nonviscous Euler equations is sufficient to trigger a simulated vortex formation and produce at least a qualitative description of this flow phenomenon.

Levels of the first five harmonics of single-rotation (SRP) and counterrotation (CRP) propeller noise, based on Hamilton Standard model test data (ref. 18), are shown in figure 25 at three axial locations in the far field: forward, aft, and in the plane of rotation. The single rotation tone levels are adjusted upward $3 \mathrm{~dB}$ to compare the equivalent of two independent prope 1 lers with the CRP $-X I$ counterrotation configuration. Single and counterrotation fundamental tones are then roughly equal, but the counterrotation harmonic levels are dramatically higher at all locations due to the unsteady aerodynamic interactions between blade rows. The high fore and aft harmonic levels must be dealt with to achieve acceptable counterrotation community noise levels. 


\section{ADVANCED CONCEPTS}

In an effort to achleve some of the swirl recovery benefit of counterrotation without the additional complexity and noise, NASA will conduct a swirl recovery vane experiment by adding swirl recovery vanes behind a singlerotation propfan model. The 1000-hp propeller test rig will be modified to accept a new balance and 8 swirl recovery vanes, as shown schematically in figure 26. These tests will evaluate the benefits of this new concept over its entire operating range up to Mach 0.85 .

Another advanced concept requiring additional research in the future is the ducted propeller, which was discussed briefly in connection with figure 3 . Ducted props are more easily integrated into the design of large long-range aircraft than unducted props because their maximum diameter requirement will be less than that of an unducted propfan. Underwing installations of propfans on large heavy aircraft are likely to be prohibitive because the large tip diameter requirements will cause ground clearance problems. There are several technical issues which must be addressed with regard to ducted props (ref. 4 ). At crulse, the drag of the large-diameter thin cowl must be kept low while maintaining acceptable near-fleld noise levels. Tradeoffs between propeller and fan aerodynamlc design methods are required to arrive at the optimum combination of ducted prop design parameters. At low-speed conditions, far-field noise in the community, cowl tip flow separation and blade stresses at high angles of attack, and reverse thrust operation are technical issues requiring further investigation.

\section{CONCLUDING REMARKS}

Propfan technology with the potential for significant fuel savings at high subsonic cruise speeds has envolved from the test of small-scale single-rotation rotor models in the late 1970's to the current flight test of large-scale complete propulsion systems of both single- and counterrotation design. The NASA PTA flight test of the 9-ft-diameter SR-7 propfan is complete, although some of the data analysis from these tests is still in work. It is clear, however, that this flight test effort met its primary objective of confirming the structural integrity of the Hamilton Standard SR-7 blade design. There was no evidence of any flutter and blade stresses were in good agreement with prediction. Preliminary indications are that propfan noise trends are also generally as predicted. The General Electric Unducted Fan engine, too, has completed its initial phase of flight test at both Boeing and Douglas as a concept demonstrator, and the PW-Allison powerplant with counterrotating Hamilton Standard propfans will enter a systems demonstration flight test phase this year on the Douglas MD-80. At NASA Lewis, the ATP effort will be concentrated on the further development of analytical codes and the wind tunnel testing of small-scale models of unique advanced concepts.

Although more work is yet to be done in ATP data acquisition, and certainly data acquisition in the related field of ducted props, the rapidly expanding ATP database will allow industry to reduce the risk involved in the hard economic decisions that must be made before implementing new airplane designs that incorporate propfan propulsion. 


\section{REFERENCES}

1. J.B. Whitlow Jr. and G.K. Sievers, "Fuel Savings Potential of the NASA Advanced Turboprop Program," NASA TM-83736, 1984.

2. G.L. Stefko, G.E. Rose, and G.G. Podboy, "Wind Tunnel Performance Results of an Aeroelastically Scaled $2 / 9$ Model of the PTA Flight Test Prop-Fan," AIAA Paper 87-1893, June 1987. (NASA TM-89917).

3. J.F. Dugan, B.A. Miller, E.J. Graber, and D.A. Sagerser, "The NASA HighSpeed Turboprop Program," SAE Paper 801120, Oct. 1980. (NASA TM-81561).

4. J.F. Groeneweg and L.J. Bober, "Advanced Propeller Research," Aeropropulsion 187, Session 5, Subsonic Propulsion Technology, NASA CP-10003-SESS-5, 1987.

5. K.R.V. Kaza, O. Mehmed, G.V. Narayanan, and D.V. Murthy, "Analytic Flutter Investigation of a Composite Propfan Model," AIAA Paper 87-0738, Apr. 1987. (NASA TM-88944).

6. M.A. Ernst and L.J. Kiraly, "Determining Structural Performance," Aeropropulsion ' 87 , Session 2, Aeropropulsion Structures Research, NASA CP-10003SESS-2, 1987.

7. J.H. Dittmar and D.B. Stang, "Cruise Noise of the $2 / 9$ Scale Model of the Large-Scale Advanced Propfan (LAP) Propeller, SR-7A," AIAA Paper 87-2717, Oct. 1987. (NASA TM-100175).

8. D.A. Sagerser and S.G. Ludemann, "Large-Scale Advanced Propfan (LAP) Program Progress Report," AIAA Paper 85-1187, July 1985. (NASA TM-87067).

9. C.C. Withers, H.W. Bartel, J.E. Turnberg, and E.J. Graber, "Static Tests of the PTA Propulsion System," AIAA Paper 87-1728, June 1987.

10. E.J. Graber, "Overview of NASA PTA Propfan Flight Test Program," Aeropropulsion '87, Session 5, Subsonic Propulsion Technology, NASA CP-10003SESS-5, 1987.

11. J.P. Hancock, "PTA Test Bed Aircraft Engine Inlet Model Test Report, Revised," LG85ER0012, Lockheed-Georgia Co., Marietta, GA, May 1985, NASA CR-174845.

12. C.M.J. Jenness, "Propfan Test Assessment Aircraft Flutter Model Test Report," LG85ER0187, Lockheed-Georgia Co., Marietta, GA, June 1986, NASA CR-179458.

13. A.S. Aljabri and B.H. Little, Jr., "High Speed Wind Tunnel Tests of the PTA Aircraft," SAE Paper 861744, Oct. 1986.

14. A.S. Aljabri, "Measurement and Prediction of Propeller Flow Field on the PTA Aircraft' at Speeds of up to Mach 0.85," AIAA Paper 88-0667, Jan. 1988.

15. A. Adamson and A.R. Stuart, "Propulsion for Advanced Commercial Transports," AIAA Paper 85-3061, Oct. 1985. 
16. B.R. Delaney, C. Balan, H. West, F.M. Humenik, and G. Craig, "A Model Propulsion Simulator for Evaluating Counter Rotating Blade Characteristics," SAE Paper 861715, Oct. 1986.

17. H.S. Wainauski and C.M. Vaczy, "Aerodynamic Performance of a Counter Rotating Prop-Fan," AIAA Paper 86-1550, June 1986.

18. B. Magliozzi, "Noise Characteristics of Model Counter-Rotating Prop-Fans," AIAA Paper 87-2656, Oct. 1987.

19. M.L. Celestina, R.A. Mulac, and J.J. Adamczyk, "A Numerical Simulation of the Inviscid Flow Through a Counterrotating Propeller," Journal of Turbomachinery, Vol. 108, No. 4, Oct. 1986, pp. 187-193.

ROUTE TO IMPROVED FUEL EFPICIENCY

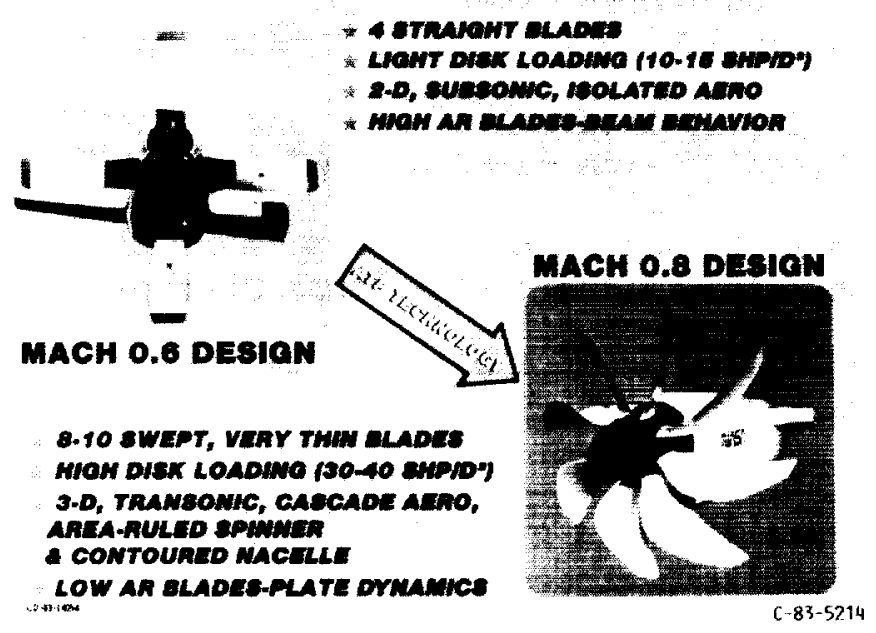

FIGURE 1. - ROUTE TO IMPROVED FUEL EFFICIENCY.

ORIGINAL PAGE IS

OE POOR QUALITY 
ORIGINAB: TAOSE IS OF POOR QUALITY

potental Fuel savinas

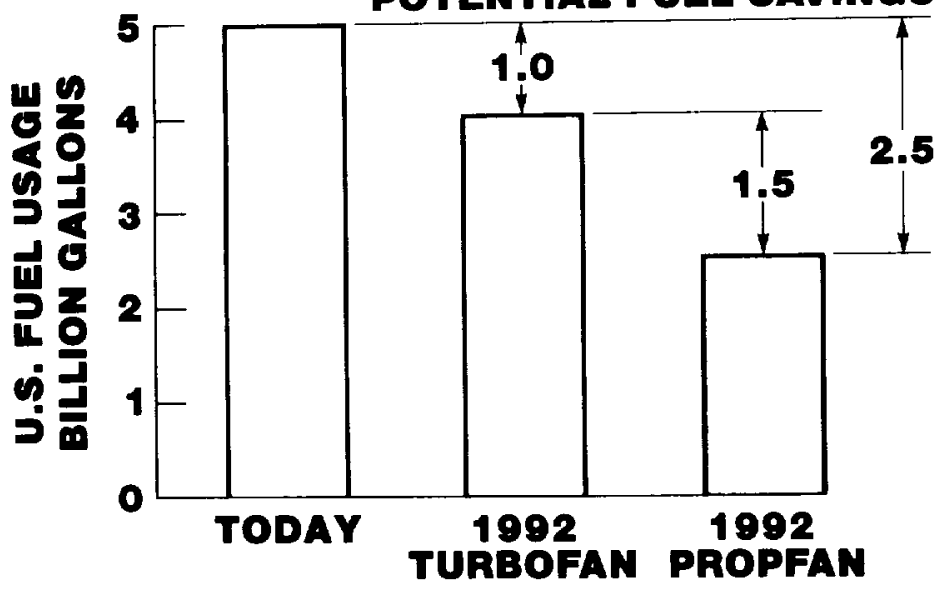

C-85-8502

FIGURE 2. - PROPFAN FUEL SAVINGS POTENTIAL FOR CURRENT U.S, $727 /$ 737/DC-9/MD-80 FLEET.

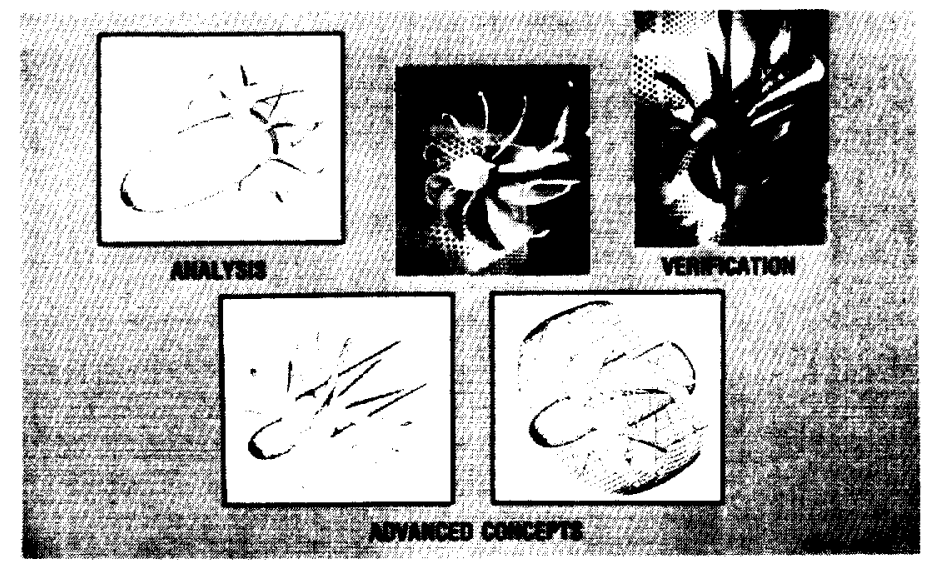

FIGURE 3. - PROPELLER RESEARCH AREAS AT NASA LEWIS RESEARCH CENTER .

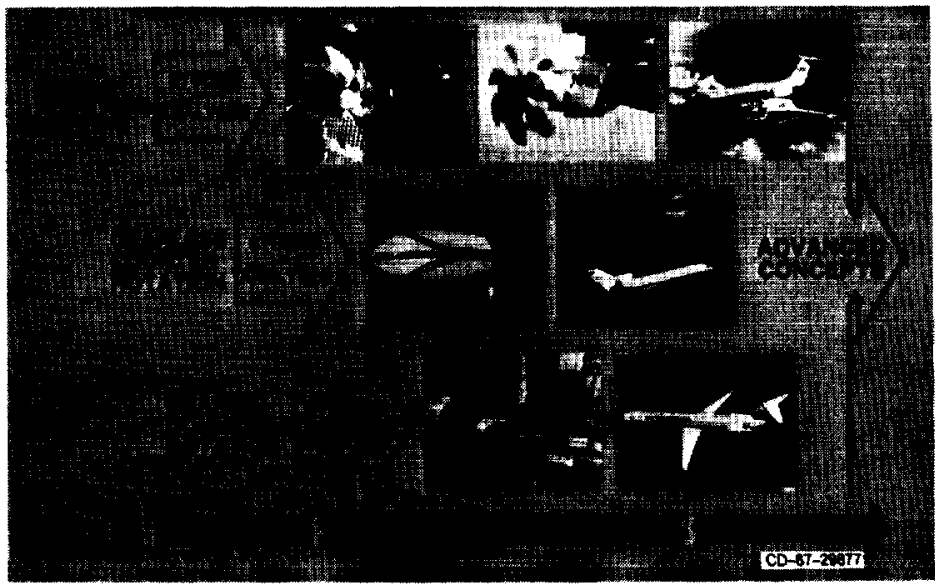

FIGURE 4. - NASA/INDUSTRY ADVANCED TURBOPROP (ATP) PROGRAM. 


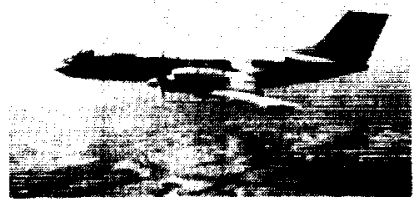

PTAVGULFSTREAM GII

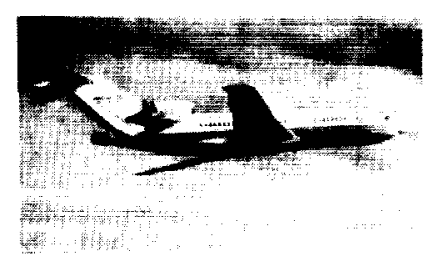

UDF/BOEING 727

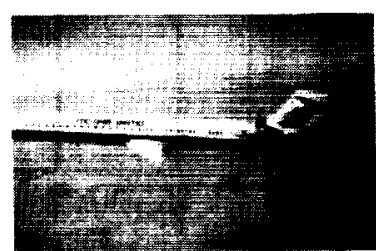

UDF/MD-80 AND

578DX/MD-80

FIGURE 5 . - HIGHI ILSIING OF AIVANCED IURBOPROPS.

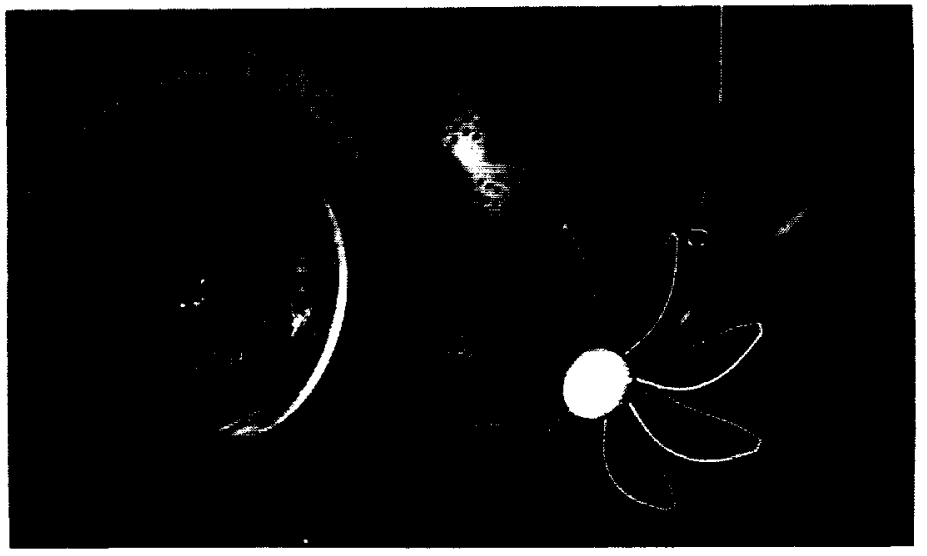

FIGURE 6. SR-/A PROPF AN MODEI. IN NASA I HWIS $8 \times 6$ I WIND TUNNEL.

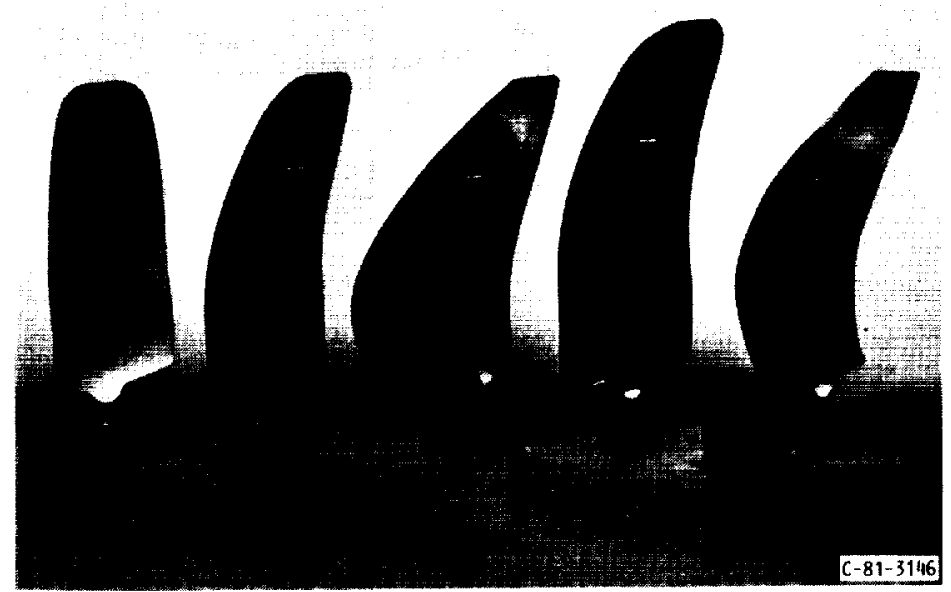

FIGURE 7. - ADVANCED PROPELLLLR BLADI WIND) IUNNEL MODELS. 


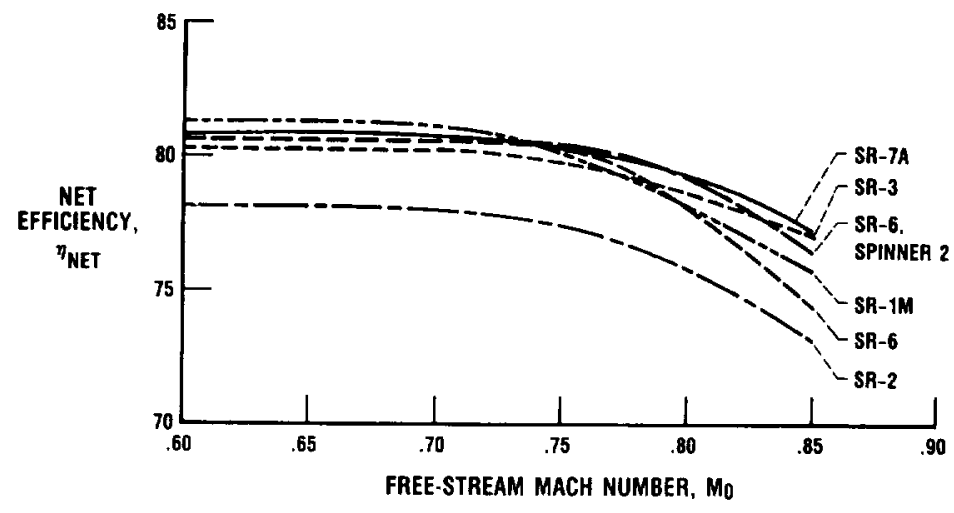

CD-88-32892

FIGURE 8. - SINGLE-ROTATION PROPELLER PERFORMANCE.

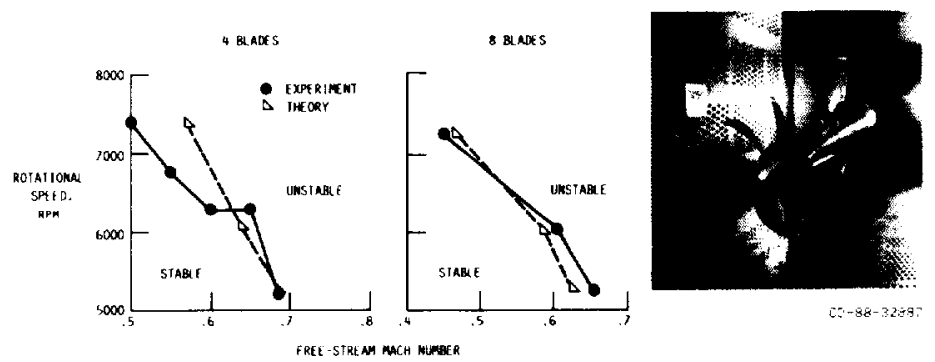

FIGURE 9. - COMPARISON OF MEASURED AND CALCULATED FLUTTER BOUNDARIES WITH SR3C-X2 PROPFAN MODEL.

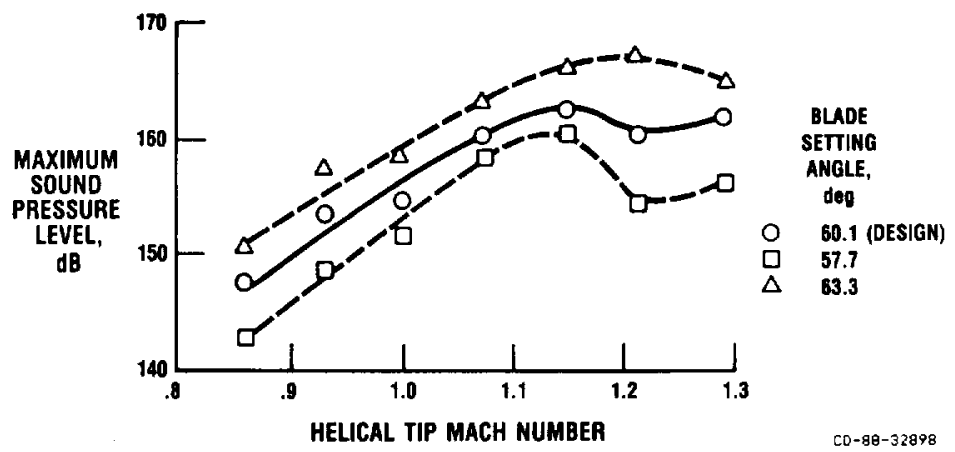

FIGURE 10. - SR-7 PEAK BLADE PASSING TONE VARIATION WITH HELICAL TIP MACH NUMBER. 


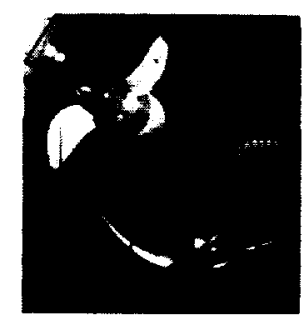

TWO-BLADE SR-7 IN MODANE, FRANCE, WIND TUNNEL

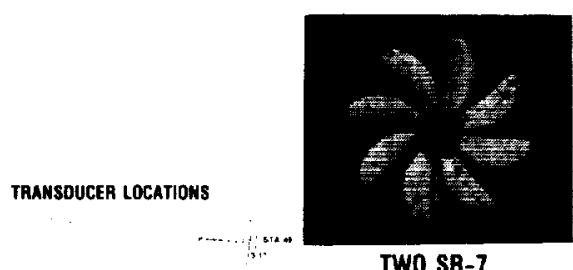

TWO SR-7

ASSEMBLIES

DELIVERED

FIGURE 11. - NASA LARGE-SCALE ADVANCED PROPELLER (LAP) PROJECT HIGHL IGHTS.

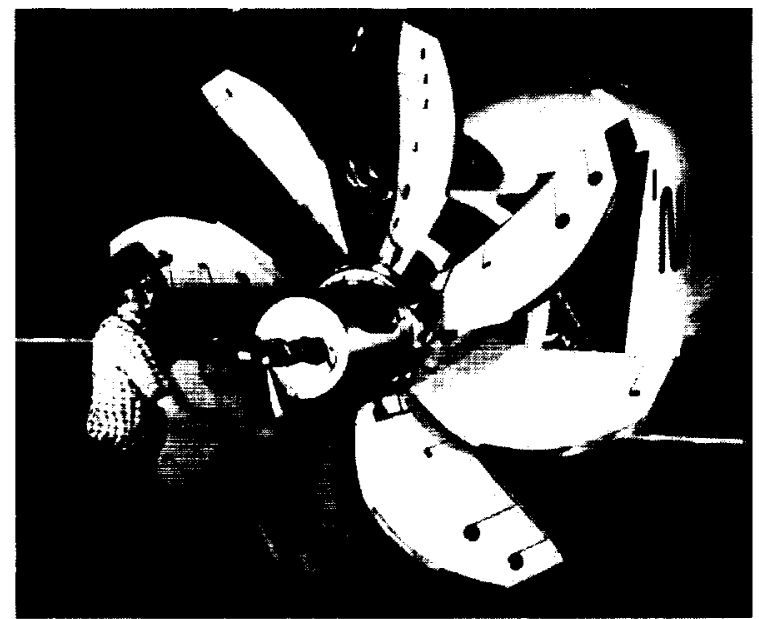

co-88-32889

FIGURE 12. - INSTRUMENTED LAP (SR-7 PROPFAN) INSTALLED ON PTA AIRCRAFT.

ORTERS:

OS Frin:
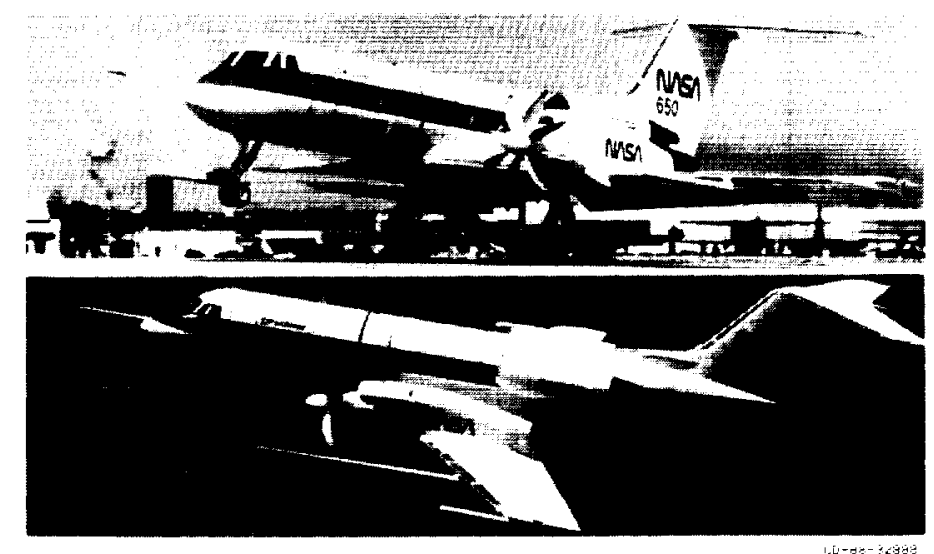

FIGURE 13. - PROPFAN IEST ASSESSMENT (PTA) FLIGHT IESTING. 


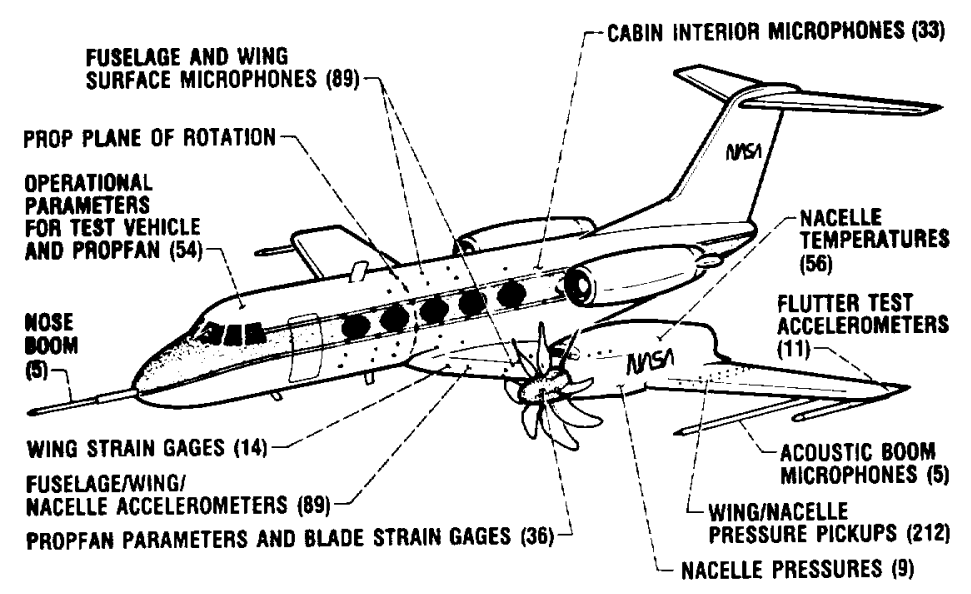

FIGURE 14. - PTA FLIGHT RESEARCH INSTRUMENTATION.

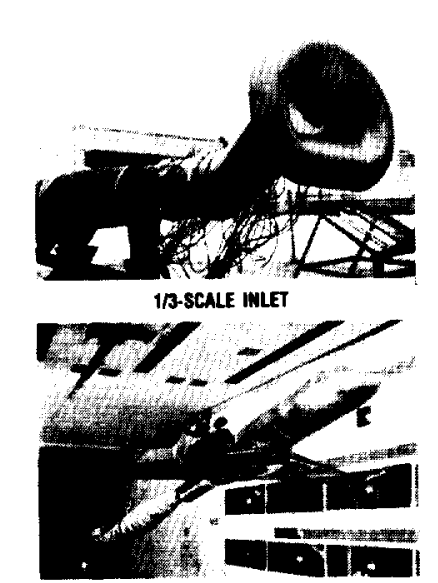

1/9-scale stabiuty, Control, and Performance

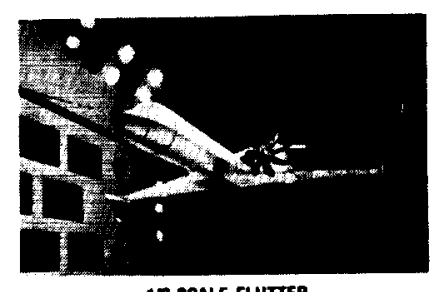

19-SCALE FLUTIEA

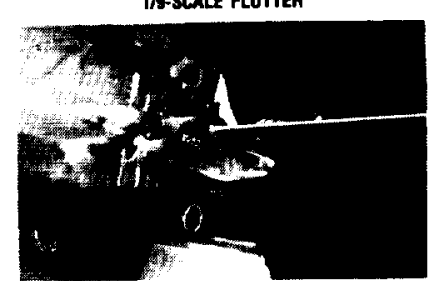

19-SCALE PROP FLOWFIELD

FIGURE 15. - PTA SCALE-MODEL TESTING. 


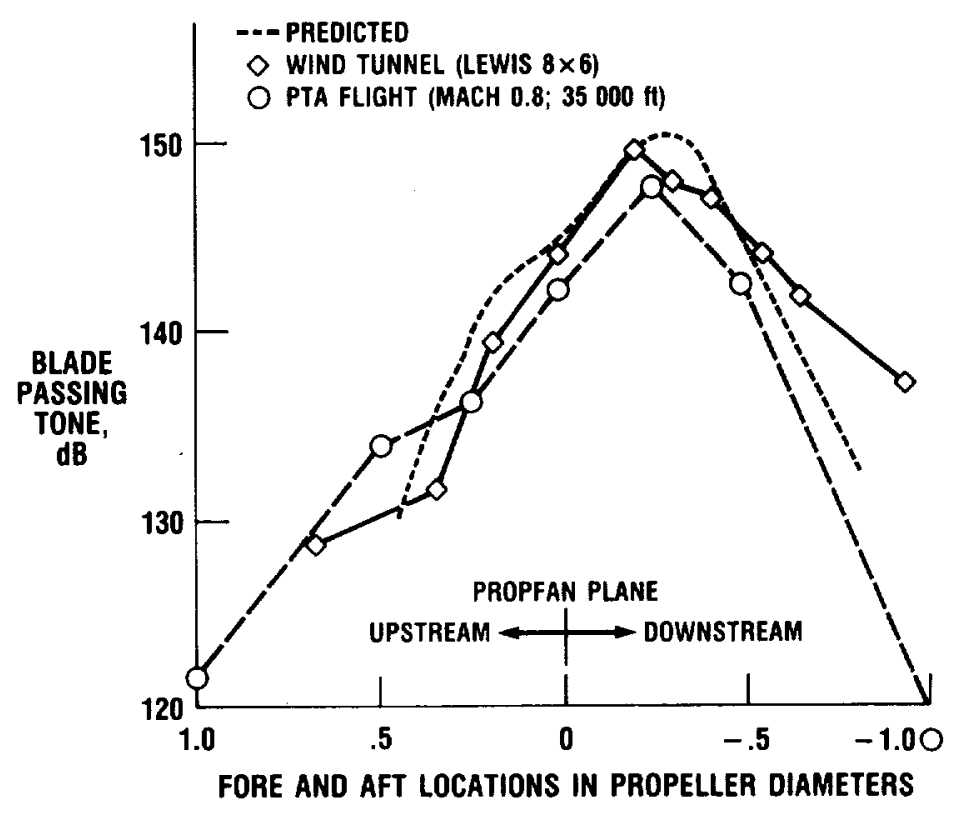

FIGURE 16. - COMPARISON OF PTA FUSELAGE SURFACE NOISE WITH PREDICTION AND WIND TUNNEL DATA.

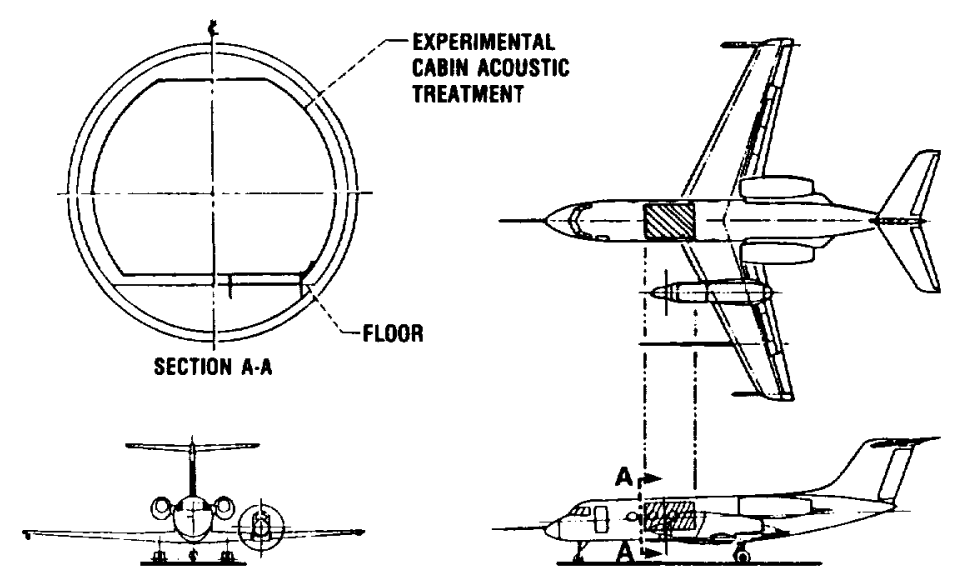

FIGURE 17. - PTA CABIN ACOUSTIC ENCLOSURE. 
ORIGTNAI PAGE IS OF POOR WUALITY.

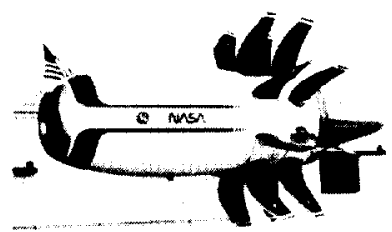

ge static test at PEebles, OHIO

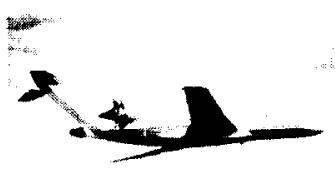

BOEING 727 FLIGHT

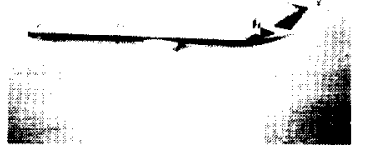

DOUGLAS MD-80

FIGURE 18, - NASA/GENERAL ELECTRIC UNDUCTED FAN ENGINE GROUND AND FLIGHT TESTING.

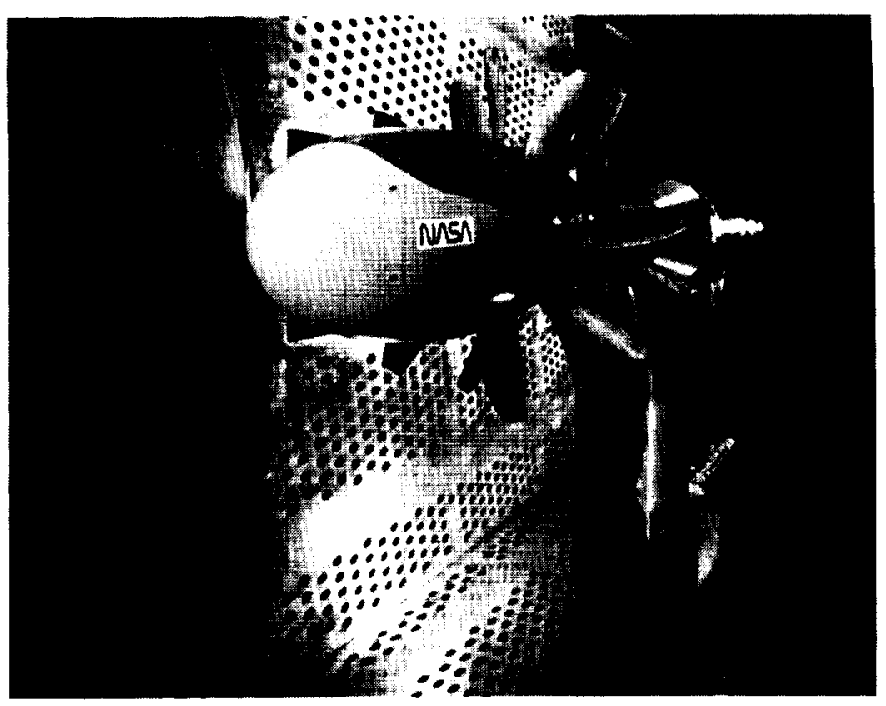

FIGURE 19. - UDF COUNTERROTATION PROPEILER MODEL. IN NASA LEWIS $8 \times 6$ FT WIND TUNNEL. 

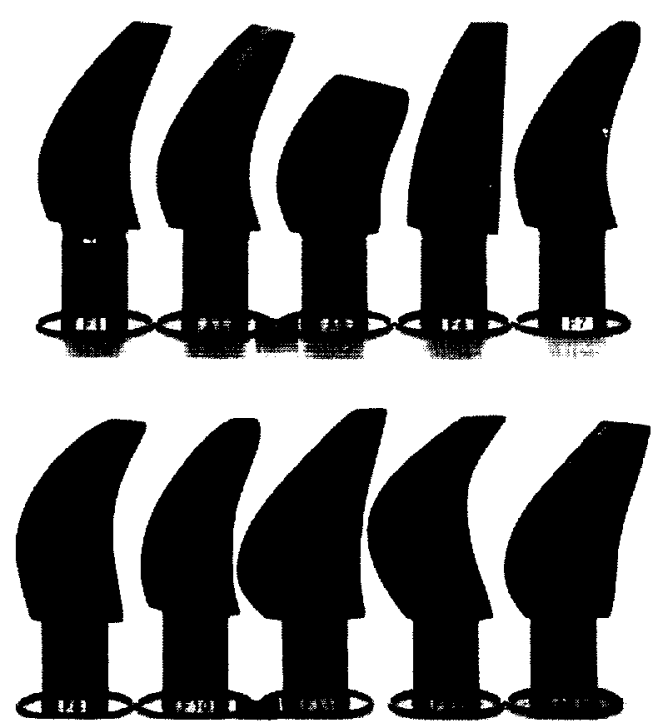

$[0-38-32900$

FIGURE 20. - WIND TUNNEL MODELS OF UDF COUNTERROTATION BLADE CONFIGURATIONS.

ORIGINAL PAGE IS

OE POOR QUALITY

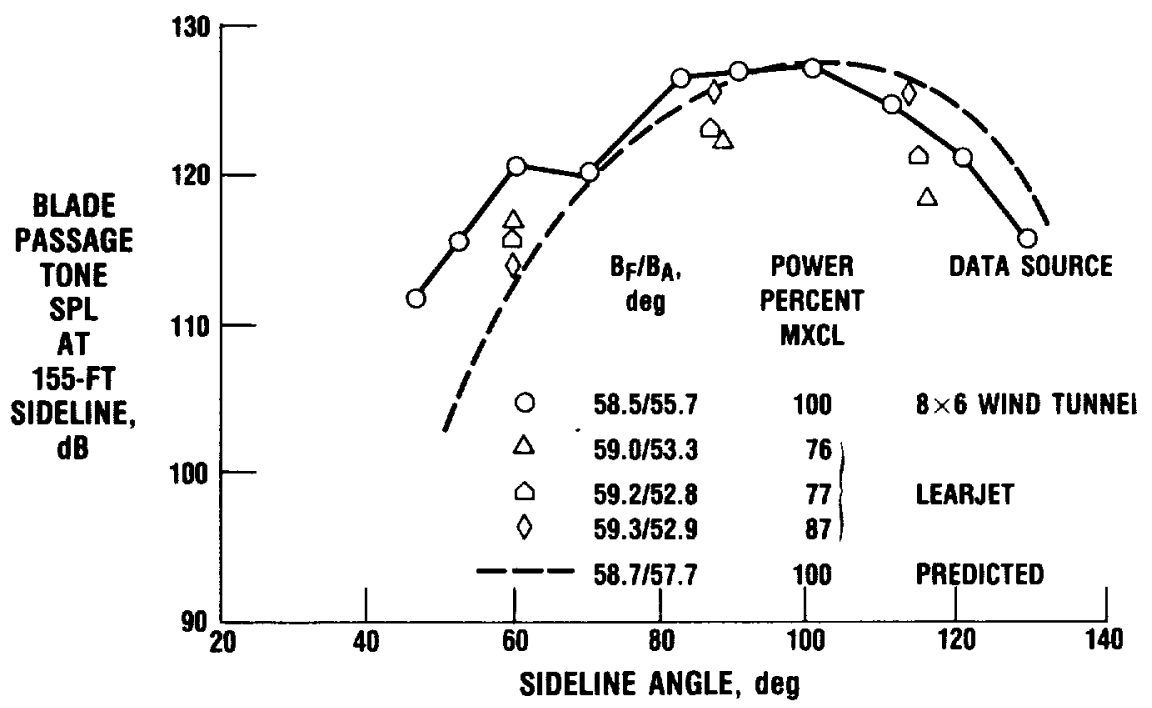

FIGURE 21. - UDF FUMDAMENTAL IONE DIRECTIVITY MEASURED IN FLIGHT, COMPARED WITH SCALED MODEL DATA AND PREDICIION. 

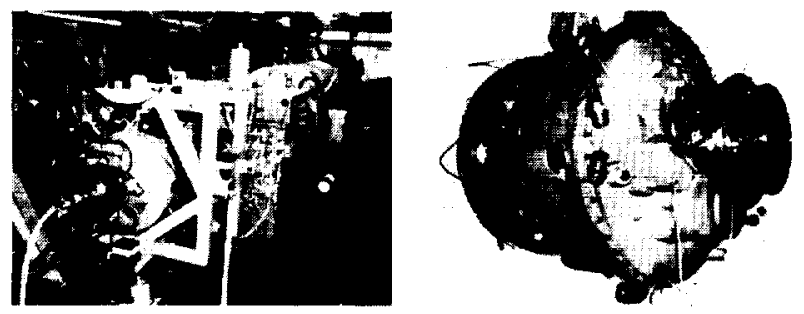

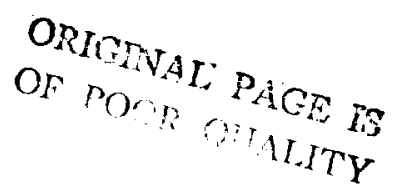

- ALLISON CONTRACT

- COUNTERROTATING IN-LINE DIFFERENTIAL PLANETARY GEAR SYSTEM

- 13 000-shp CLASS

- 99 PERCENT EFFICIENCY

- DURABILITY GOAL OF 30 000-hr MTBR

FIGURE 22. - NASA/ALLISON ADVANCED GEARBOX TECHMOLOGY COUNTERROTATION GEARBOX TESTING.

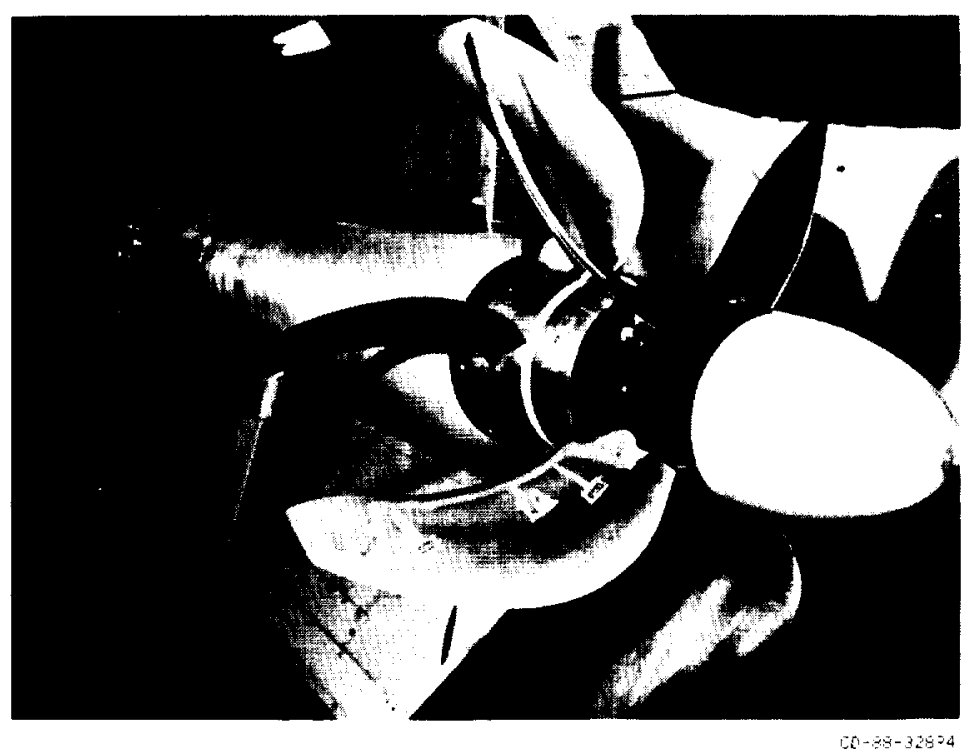

FIGURE 23. - HAMILTON STANDARD CRP-X1 COUNTERROTATION PROPFAN MODEL IN UTRC WIND TUNNEL. 


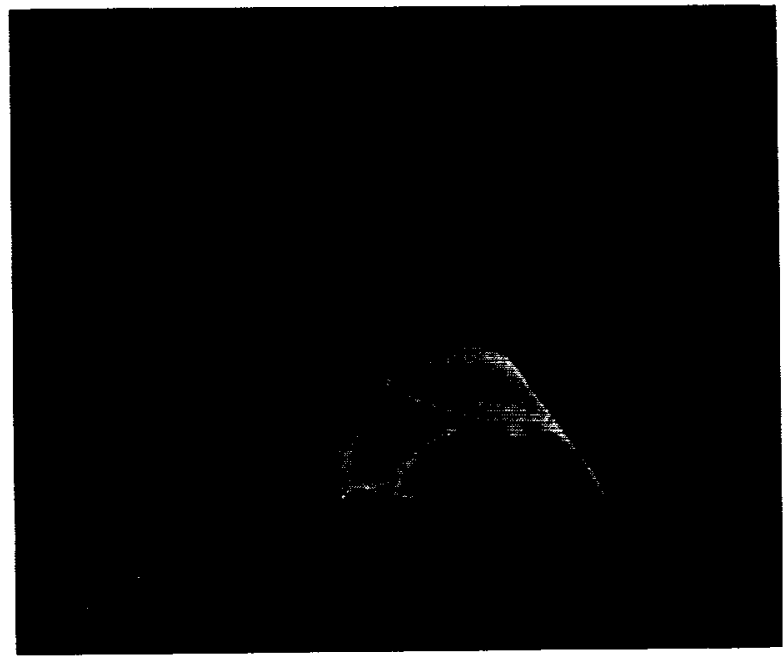

CD-88-32901

FIGURE 24. - NASA LEWIS PREDICTION CODE SIMULATES LEADING EDGE AND TIP VORTEX SHEDDING AT OFF-DESIGN CONDITIONS FOR CRP-X1 PROPFAN.

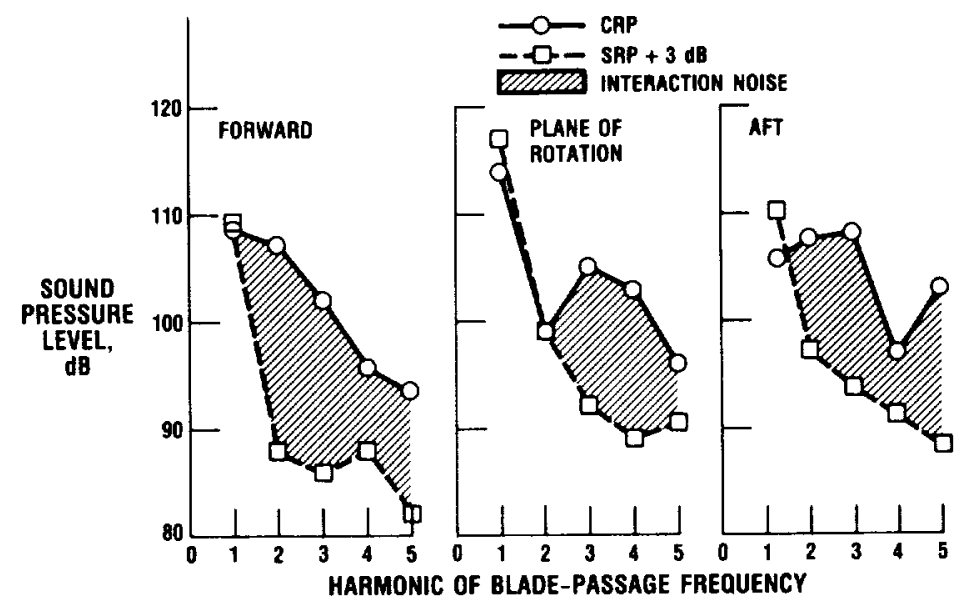

FIGURE 25. - CRP-X1 MODEL NOISE IEST DATA COMPARED WITH ADJUSTED SINGLE-ROTATION PROPFAN DATA.

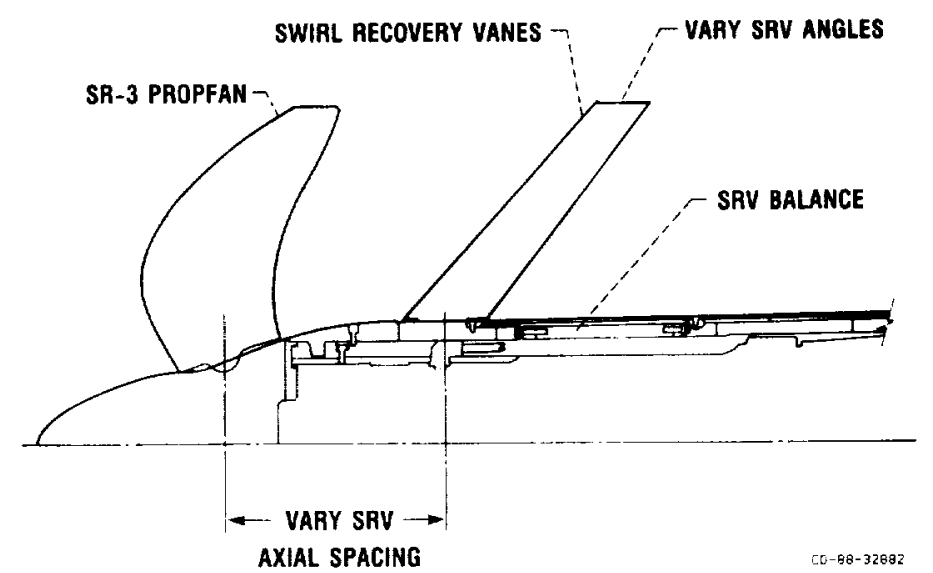

FIGURE 26. - NASA LEWIS SWIRL RECOVERY VANE EXPERIMENT. 


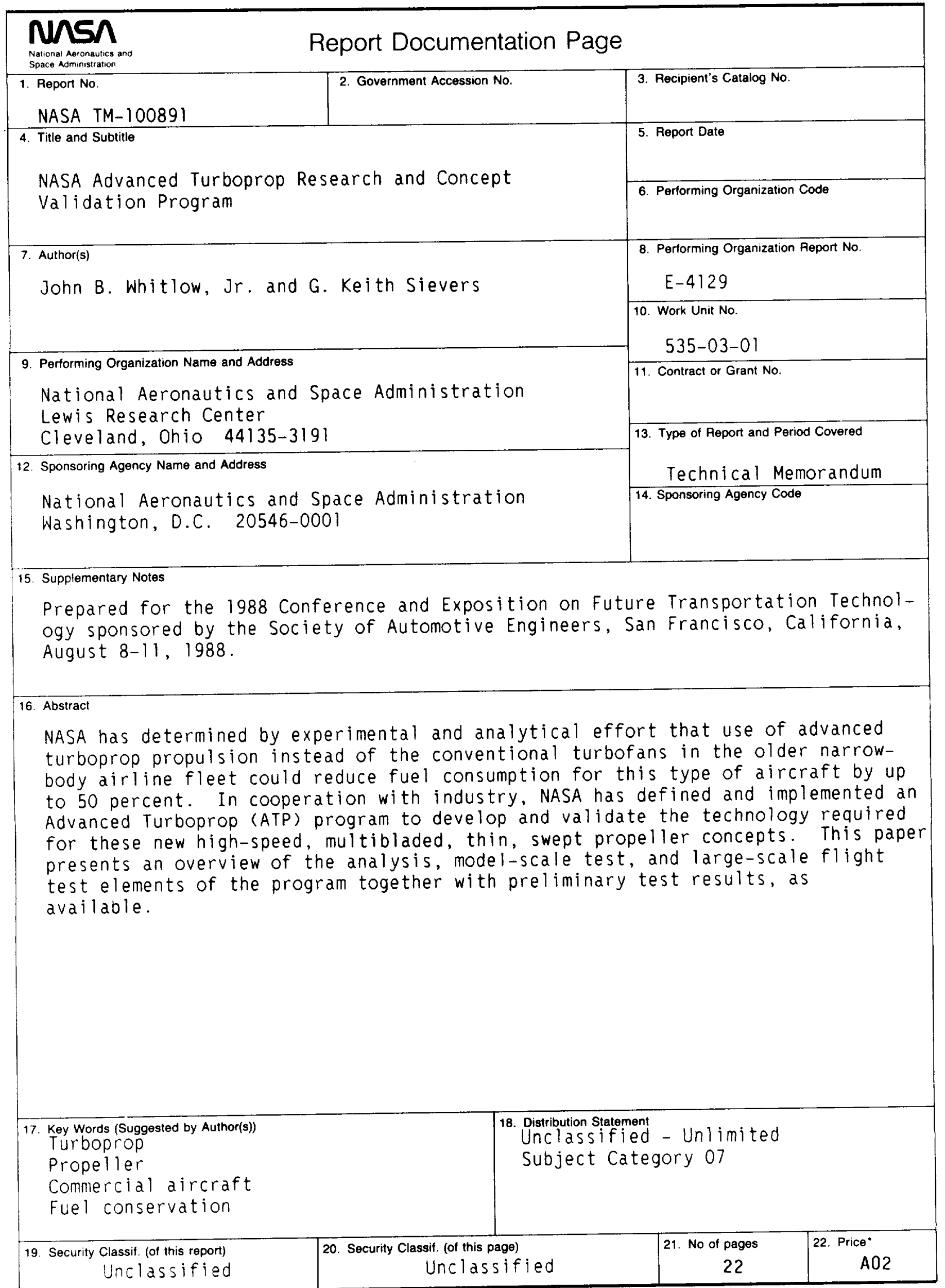




National Aeronautics and

Space Administration

Lewis Research Center

Cleveland. Ohio 44135

Onclal Bueinees

Penaly lor Potrate Uas \$800
ADDRESS CORRECTION REQUESTED

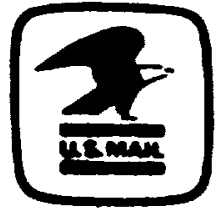

Postage and Foes Paid

National Aeronautice and

Spece Administration

NASA-451 